\title{
Prática Libertadora: expandindo o mundo através da educação
}

Liberating Practice: expanding the world through education

\section{Atos Edwin Pereira da Silva Lucas atos.flum@gmail.com}

Licenciando em Letras - Português e Literaturas pela PUC Rio

\author{
Giovane de Souza Amaro \\ giovanes.amaro@gmail.com \\ Licenciando em Letras - Português e \\ Literaturas pela PUC Rio
}

\section{Vitor Azevedo Abou Mourad vitorabou124@gmail.com}

Licenciando em Letras - Português e Literaturas pela PUC Rio

\author{
Resumo \\ Neste artigo, pretendemos refletir sobre a construção, no Brasil, de uma educação libertadora, \\ por meio de um ensino voltado para a esperança, a leitura crítica e a união. Para isso, buscamos \\ aparato histórico, teórico e prático que não apenas exemplificam as palavras de Paulo Freire e \\ Dom Paulo Evaristo Arns, como também denotam sua relevância em pensar sobre educação e \\ transformação social. \\ Palavras-chave: Paulo Freire; leitura; reflexão; libertação.
}

\begin{abstract}
This article aims to reflect on the construction, in Brazil, of a liberating education, through teaching with focus on hope, critical reading and unity. To this aim, we seek historical, theoretical and practical apparatus that not only exemplify the words of Paulo Freire and Dom Paulo Evaristo Arns, but also show their relevance in thinking about education and social transformation.
\end{abstract}

Keywords: Paulo Freire; reading; reflection; release. 
MOURAD, Vitor Azevedo Abou; LUCAS, Atos Edwin Pereira da Silva; AMARO, Giovane de Souza. Prática Libertadora: expandindo o mundo através da educação. Dignidade Re-Vista, v.7, n.12, jul 2021.

\section{Introdução}

Dom Paulo Evaristo Arns e Paulo Freire, se vivos, completariam 100 anos em 2021 e certamente teriam muito a dizer sobre o atual momento. $\mathrm{O}$ que Freire diria sobre o ensino remoto? E o que Dom Paulo Evaristo Arns falaria sobre a situação dos mais pobres em meio a tantas dificuldades? Não temos como saber exatamente quais seriam as respostas a estas perguntas, mas o que esses dois grandes Paulos fizeram e produziram serve, até os dias de hoje, como forma de reflexão e aprendizado, além de ser um estímulo para a transformação da sociedade.

Dom Paulo Evaristo Arns foi, entre as décadas de 1960 e 1970, bispo e arcebispo de São Paulo, destacando-se na resistência contra as práticas de tortura da Ditadura Militar. Ficou conhecido por ter celebrado, em 1975, o marcante culto ecumênico em honra do jornalista Vladimir Herzog, morto pelo regime, além de ter tecido duras críticas à Ditadura. Arns defendeu, durante toda a sua vida, os Direitos Humanos para todas as pessoas, com uma atenção especial aos mais pobres, colocados à margem da sociedade. Dedicou-se às periferias por muitos anos, porém buscava dialogar, também, com indivíduos de outros grupos e classes sociais, pedindo que assumissem "de verdade um papel de sujeito histórico de transformações" (Altemeyer Jr, 2020, p.33). Dessa maneira, seu lema cardinalício, “De esperança em esperança", tornou-se a sua missão de vida, semeando, por onde passava, a semente da esperança de um mundo melhor.

Outro ilustre brasileiro que dedicou sua vida à batalha por direitos foi Paulo Freire, com uma atenção voltada à educação. O recifense, criador de um método pioneiro de alfabetização de adultos no país, foi e ainda é reconhecido mundialmente pelo seu trabalho voltado a uma educação libertadora (Freire, 2020) e humanizadora. Por isso, as ideias de Freire são extremamente atuais: “Nesta direção, o pensamento freireano é novo, não é novidade. Ele é um clássico, sem ter se emoldurado num processo de engessamento. $\mathrm{O}$ pensamento de Freire continua animado. Paulo Freire nos anima" (Cortella, 2011, p.12). As ideias do educador permanecem vivas, pois são, no atual contexto, de suma importância para refletirmos a educação e a sociedade brasileiras como um todo e nos inspirarmos.

Arns e Freire possuem em comum a luta pela esperança de transformação da sociedade por seus próprios indivíduos e por meio do diálogo, da liberdade e do amor. Buscamos, neste artigo, refletir como uma educação que promove a esperança e a libertação, de fato, pode ser construída. Nesse sentido, o que desejamos é buscar possíveis entendimentos acerca das contribuições desses dois Paulos para uma possível transformação do Brasil e do mundo. 
MOURAD, Vitor Azevedo Abou; LUCAS, Atos Edwin Pereira da Silva; AMARO, Giovane de Souza. Prática Libertadora: expandindo o mundo através da educação. Dignidade Re-Vista, v.7, n.12, jul 2021.

Para tanto, recorremos a algumas das obras de Freire $(1989,1992,2015,2020)$ que levam o leitor a refletir tanto sobre a sociedade no geral quanto sobre a sua própria prática, e autores alinhados a ele, devido às influências das obras e ao fato de ambos, Cortella (2011) e bell hooks (2017), terem tido a oportunidade de conhecer e dialogar com Freire. Além disso, para pensarmos a educação brasileira e os movimentos que têm sofrido, Alves (2001) e Vidal (2013) trazem contribuições importantes do ponto de vista filosófico e histórico, assim como Arrojo e Rajagopalan (2003) apresentam perspectivas acerca da leitura. Buscamos, ainda, trazer os diálogos entre a Prática Exploratória (Grupo da Prática Exploratória, 2020; Miller et al., 2008; Barreto; Miller; Góes Monteiro, 2015), a educação libertadora e a formação docente.

Deste modo, objetivamos analisar, a partir do histórico da educação brasileira e suas tentativas de libertação, tendo como metodologia a leitura crítico-reflexiva, como a esperança, a leitura e a união são importantes para as mudanças sociais e para (re)pensar a própria prática pedagógica, enquanto, em nosso caso, licenciandos, já inseridos em ambientes de ensino básico.

\section{A educação brasileira no caminho para a libertação}

A educação brasileira, ao longo dos tempos, passou por diversos momentos levando em conta o contexto cultural, histórico e sociopolítico. Durante bastante tempo, o país apresentou uma educação extremamente excludente, destinada apenas aos membros da elite de cada época. Uma mudança mais radical no que diz respeito ao acesso ao ensino só ocorreu em 1932, com a publicação do Manifesto dos Pioneiros da Educação Nova, escrito por 26 intelectuais e intitulado A reconstrução educacional no Brasil: ao povo e ao governo.

Tal documento, considerado à frente de seu tempo, trazia, sobretudo, ideias relacionadas à democratização do ensino, em defesa de uma “educação pública, laica, gratuita e obrigatória", (Vidal, 2013, p.583). O Manifesto objetivava uma renovação educacional no Brasil, de maneira a torná-la mais moderna e inclusiva, assim como sua sociedade, que era considerada, ainda, muito ligada a valores do passado. Um desses valores se referia ao papel destinado à ciência, que era, na época, muito pequeno, pois o pensamento cristão ainda predominava. Dessa maneira, ao priorizar a racionalidade e a ciência, o Manifesto colocava o homem como criador da sua realidade, estando em um papel ativo, cabendo a ele se adaptar às situações e, se necessário, ser a força de mudança. Essa ideia expande-se também para o âmbito educacional, em que o ensino é entendido como uma ferramenta de transformação social.

Essas mudanças pensadas a partir do Manifesto dos Pioneiros refletem as crenças deles em relação ao papel da escola e à sua importância na comunidade, estabelecendo-se um vínculo 
MOURAD, Vitor Azevedo Abou; LUCAS, Atos Edwin Pereira da Silva; AMARO, Giovane de Souza. Prática Libertadora: expandindo o mundo através da educação. Dignidade Re-Vista, v.7, n.12, jul 2021.

fundamental entre esse ambiente e a sociedade. Assim, valores importantes ganham espaço nesse pensamento, como autonomia, respeito à diversidade, igualdade e liberdade, solidariedade e cooperação social. A valorização desses princípios pode ser vista como um marco na educação brasileira, já que, anteriormente ao Manifesto, eles não eram pensados nesse contexto, em que ideais burgueses como egoísmo, individualismo e competitividade predominavam.

Entretanto, é importante pensarmos que, mesmo após a publicação do Manifesto, esses ideais continuaram - e continuam até hoje - presentes no sistema educacional brasileiro. Um reflexo dessa maneira de compreender a sociedade e, consequentemente, a educação é o estilo de aula predominante, em que ainda são comuns práticas de transmissão de conteúdos pelo professor, e posterior memorização por parte dos alunos. Assim, trazemos a voz de Paulo Freire, um dos maiores - se não o maior - brasileiros nessa área, quando diz que " a educação se torna um ato de depositar, em que os educandos são os depositários e o educador, o depositante" (2020, p.80). É nessa direção que o autor conceitua a educação bancária (Freire, 2020), compreendida como concepção em que os alunos são colocados, sem opção de escolha, muitas vezes, como receptores do conhecimento, que vem de indivíduos considerados detentores do saber.

Com efeito, Freire questiona e critica duramente esse modelo de educação, por considerálo, ainda, como uma maneira de silenciamento e de anulação do educando, colocado como mero objeto do processo de aprendizagem, sem participação ativa. Há, nesse contexto, uma imposição de conteúdos, materiais e comportamentos esperados dos educandos. Nesse sentido, “não há criatividade, não há transformação, não há saber”' (Freire, 2020, p.81), o que satisfaz totalmente os interesses dos opressores, mantendo estruturas sociais de desigualdade e exploração de camadas consideradas inferiores.

De maneira oposta à educação bancária, encontra-se a educação como prática da liberdade (Freire, 2015), que “'implica a negação do homem abstrato, isolado, solto, desligado do mundo, assim como também a negação do mundo como uma realidade ausente dos homens" (Freire, 2020, p.98). Sob esse viés, o educando e o educador, no contexto pedagógico, não são desassociados de sua vida fora de sala, sendo necessária, então, a conexão entre a vida e o que está sendo aprendido e ensinado, por meio do estímulo ao pensamento reflexivo e crítico e à postura investigativa do educando. Dessa maneira, a educação poderá servir como instrumento para a mudança da realidade, como visado pelos pioneiros de 1932, e será possível a substituição de “antigos e culturológicos hábitos de passividade, por novos hábitos de 
MOURAD, Vitor Azevedo Abou; LUCAS, Atos Edwin Pereira da Silva; AMARO, Giovane de Souza. Prática Libertadora: expandindo o mundo através da educação. Dignidade Re-Vista, v.7, n.12, jul 2021.

\section{$\underset{\text { DIGNIDADE }}{\text { DISTA }}$}

participação e ingerência'" (Freire, 2015, p.94), efetivando a importantíssima ideia de democracia.

Ademais, mergulhando na importância de se (re)pensar a educação sob uma perspectiva decolonial, bell hooks (2017), muito influenciada por Paulo Freire, destaca como a obra do autor lhe trouxe de volta a fé na educação libertadora. A autora reflete a respeito das práticas engajadas de ensino na era do multiculturalismo, diante de questões de raça e gênero, por exemplo, em sala de aula. Para a construção dessa pedagogia transformadora, hooks enfatiza a importância do diálogo, também apresentada por Freire (2020). Segundo ele, é impossível dissociar o amor do diálogo, sendo os dois fundamentais no processo de ensino-aprendizagem.

Nessa direção, “a educação é um ato de amor, por isso, um ato de coragem. Não pode temer o debate. A análise da realidade. Não pode fugir à discussão criadora, sob pena de ser uma farsa'" (Freire, 2015, p.97). Educar é, portanto, comprometer-se com a causa de libertação, empenhando-se por meio da conversa e das trocas dialógicas com as demais pessoas. Aqui, os educandos são ainda mais importantes, pois é a partir da conversa com eles que se inicia o processo de ensino-aprendizagem, de maneira mútua, indo e vindo dos dois lados. Com isso em mente, é fundamental, também, pensar como a leitura está presente na sala de aula bancária e na sala de aula que aspira à libertação.

\section{Leitura: do mundo à palavra}

Os estudos em leitura são bastante antigos na Educação e na Linguística, passando por diferentes perspectivas e abordagens. O que determina a leitura de uma mensagem? O contexto influencia neste processo? Quando estamos lendo um texto, no que estamos focando? Lemos apenas textos verbais ou também imagens, situações, objetos? É possível ler o mundo? Pensar essas questões e outras tantas é refletir acerca das diferentes conceituações de leitura, desde o senso comum, considerando-a como a capacidade de ler um texto, passando por noções literárias, que relacionam ao entendimento individual de algo, não necessariamente por uma mensagem verbal. É por esse caminho que Freire nos leva à reflexão sobre o ato de ler.

Temos duas concepções principais acerca da leitura e de seus significados. A primeira, enxergando como impossível a distinção entre sujeito e objeto, considera que as leituras feitas por um sujeito estão determinadas por seus aspectos históricos, sociais, psicológicos etc. Dessa maneira, ler é construir significados, e não os descobrir. Cada indivíduo, então, poderá fazer essa produção de uma maneira, não sendo razoável julgar uma leitura como absolutamente correta ou incorreta. 
De maneira oposta a essa concepção, encontra-se a logocêntrica, que acredita ser possível descobrir e ter significados independente do sujeito, das questões socioculturais e da maneira da leitura. Assim, a leitura é a descoberta dos significados que já estão presentes, dados no texto, sendo possível considerar uma leitura correta ou incorreta, sem precisar levar em conta a perspectiva empregada. Essa concepção “ pressupõe, em outras palavras, a possibilidade de que um leitor, no exato momento da leitura, pudesse esquecer de tudo que o constitui como sujeito: seu inconsciente, sua história, sua cultura, sua ideologia', (Arrojo; Rajagopalan, 2003, p.88).

A obra de Paulo Freire, até certo ponto, se adequa à primeira concepção e, portanto, promove a quebra com a concepção logocêntrica. Em seu livro A importância do ato de ler em três artigos que se completam (1989), Freire denota o valor inestimável da leitura na vida de uma pessoa e marca o ato de ler, antes de tudo, como a capacidade de ler o mundo e tudo o que o norteia: “A leitura do mundo precede a leitura da palavra, daí que a posterior leitura desta não possa prescindir da continuidade da leitura daquele. Linguagem e realidade se prendem dinamicamente" (Freire, 1989, p.9).

Indo na contramão do que é dito por Freire, uma visão mais engessada do ato de ler é encontrada em materiais didáticos e no pensamento de professores, o que pode acarretar no entendimento de que é possível se ter apenas uma interpretação acerca de uma mensagem. Isso faz com que muitos professores, nessa concepção bancária de educação, julguem como equivocadas leituras que os alunos fazem, e impõe sua autoridade e a crença de que o professor é o detentor do conhecimento e, dessa maneira, superior aos alunos, que são inferiorizados e ignorados enquanto indivíduos. A verdade é que perdemos muito ao enquadrar algo tão dinâmico como a leitura.

Paulo Freire (1989) também coloca o movimento dinâmico do ato de ler como um importante aspecto no processo de alfabetização, o que valoriza a experiência existencial do aluno e não a experiência do educador, além de colocar a leitura em uma posição de ato político, já que é através dela que o indivíduo será capaz de entender o mundo. O autor destaca o papel do educador, que deve atuar em prol de uma prática educadora de libertação, levando os alunos à expansão do conhecimento, em que eles são o sujeito e também o criador. Em Freire, os alunos não podem ser ignorados, mas sim estimulados ao pensamento crítico e à formação enquanto cidadãos. Além disso, o ensino e, consequentemente, as leituras devem estar inseridos em seus contextos, para que o que é ensinado na escola não permaneça lá, mas seja colocado em prática. Logo, impor aos alunos uma determinada interpretação é considerá-los incapazes de produzir seus próprios sentidos e leituras, mantendo uma estrutura tradicional e bancária. 


\section{Esperançar e prática exploratória}

Após cem anos de história, Freire e Dom Paulo Arns, com a relevância de suas obras, ainda nos convidam a refletir sobre a forma como as práticas educacionais são realizadas e a importância de uma boa relação, por meio delas, entre a vida de educadores e educandos. Hoje, um dos grandes convites do pedagogo e do arcebispo, para nós, poderia ser a esperança.

Com Dom Paulo, somos levados a viver "de esperança em esperança”, o que pode ser ótimo, pois, diante de tantos desafios que temos enfrentado, viver dessa forma talvez seja o que nos motive a continuar a prática educacional. Entretanto, a esperança sozinha não é suficiente, pois não é a esperança que pode mudar o contexto em que estamos inseridos. Como afirma Freire (1992), a esperança do verbo esperar só espera. Segundo o autor, precisamos ter esperança do verbo esperançar, pois essa é a esperança que levanta e vai atrás, que constrói e que não desiste. Talvez seja do esperançar que precisamos em nosso dia a dia, pois é através dele que podemos nos levantar e (re)construir a nossa prática para enfrentar a incerteza que nos assola.

Diante de tamanho desafio, baseamo-nos na filosofia da Prática Exploratória (PE), que, para Miller et al. (2008, p.146, grifos do autor), “é uma maneira indefinidamente sustentável em que professores e alunos, dentro de suas salas de aula e enquanto trabalham no processo de aprender e ensinar, se engajam para desenvolver o seu entendimento da vida na sala de aula". Sendo assim, a PE instiga professores e alunos a desenvolverem, juntos, um olhar investigativo para a sala de aula, a fim de que possamos trabalhar e tentar entender o que se desenvolve nesse ambiente. Para que esses entendimentos sejam explorados, vivemos, então, os princípios propostos pela PE, que são:

Priorizar a qualidade de vida.

Trabalhar para entender a vida na sala de aula ou em outros contextos profissionais.

Envolver todos neste trabalho.

Trabalhar para a união de todos.

Trabalhar para o desenvolvimento mútuo.

Integrar este trabalho com as práticas de sala de aula ou com outras práticas profissionais.

Fazer com que o trabalho para o entendimento e a integração sejam contínuos. (Miller et al., 2008, p.147, grifos do autor)

Com as reflexões propostas por esses princípios, podemos tentar construir uma educação mais humanizada, que prioriza a qualidade de vida de todos os que estão envolvidos e que busca entender e refletir sobre os possíveis conflitos que podem surgir ao longo do tempo. Dessa 
MOURAD, Vitor Azevedo Abou; LUCAS, Atos Edwin Pereira da Silva; AMARO, Giovane de Souza. Prática Libertadora: expandindo o mundo através da educação. Dignidade Re-Vista, v.7, n.12, jul 2021.

forma, sob as lentes da reflexão e do trabalho em conjunto entre educadores e educandos, a vida em sala de aula e na sociedade em que vivemos pode ser mais dialógica, libertária e amorosa, assim como desejavam Freire e Arns.

Em contribuição para a construção de uma educação libertadora, na PE, todos somos aprendizes (Grupo da Prática Exploratória, 2020). Alunos, professores, mestres ou doutores, todos estamos em um lugar de aprendizagem e, por isso, enquanto educamos, somos educados, e, enquanto somos educados, também educamos (Freire, 2020). A PE realiza a superação da “contradição educador-educandos" (Freire, 2020, p.95) participando da educação problematizadora e rompendo com a imposição da educação bancária, dominante e antidialógica.

Ao viver a Prática Exploratória, vivemos, também, a proposta de Paulo Freire e Dom Paulo Arns, pois, por meio dela, experimentamos a prática libertadora e esperançosa, em uma vivência saudável, conjunta, dialógica e em constante desenvolvimento.

\section{O papel do licenciando diante da Educação Libertadora}

Pensar a educação como prática da liberdade e os princípios da Prática Exploratória nos leva a diversas reflexões sobre como foi o nosso ensino-aprendizagem e como esse processo ocorre nos dias de hoje. E por que não sobre como podemos fazer daqui para frente? Por isso, buscamos, aqui, trazer o papel que acreditamos que nós, licenciandos, ocupamos diante de uma educação ainda bancária e, muitas vezes, repressora da liberdade e da autonomia do aluno.

Nesse sentido, nos inserimos enquanto licenciandos de Letras da PUC-Rio, já tendo passado pelas disciplinas de Estágio Supervisionado de Português e por termos experiência em programas que objetivam justamente a inserção do licenciando na escola pública: o PIBID (Programa Institucional de Bolsas de Iniciação à Docência) e o Programa de Residência Pedagógica, ambos da CAPES (Coordenação de Aperfeiçoamento de Pessoal de Nível Superior). Nesses projetos, alunos de licenciatura recebem bolsas para atuar em escolas públicas, com a supervisão de um professor da unidade e com a coordenação de docentes da instituição de ensino superior. A ideia de ambos os projetos é que o graduando tenha uma participação mais ativa, não apenas observando a aula do professor regente, mas também fazendo intervenções, propondo atividades e conduzindo algumas aulas.

Dessa maneira, é possibilitada uma vivência ao graduando ainda em sua formação inicial, que é fundamental, agregando experiências e reflexões tanto sobre o funcionamento do ambiente escolar, quanto sobre as relações dentro e fora de sala de aula. Com isso, licenciandos 
MOURAD, Vitor Azevedo Abou; LUCAS, Atos Edwin Pereira da Silva; AMARO, Giovane de Souza. Prática Libertadora: expandindo o mundo através da educação. Dignidade Re-Vista, v.7, n.12, jul 2021.

ocupam um entrelugar, pois, na universidade, estão sentados nas cadeiras - muitas vezes enfileiradas - destinadas aos alunos, enquanto, na escola, possuem uma autonomia maior para estar à frente da turma, em uma versão mais tradicional, ou junto dela, atuando como um mediador do conhecimento.

Feita a apresentação de nossas vozes, é válido destacar a importância do trabalho com a Prática Exploratória na formação inicial de professores. A PE não se propõe a ser uma metodologia a ser seguida em sala de aula, mas sim uma forma de estar em sala de aula - e fora dela também -, uma percepção atenta que os aprendizes podem construir juntos (Miller et al., 2008). Os licenciandos de Letras da PUC-Rio têm contato com a PE desde o início da graduação, o que estimula o pensamento crítico-reflexivo enquanto alunos e enquanto professores em formação, buscando questionar o que é/foi possível entender a partir de dada atividade ou acontecimento no contexto pedagógico. Assim, demonstra-se o trabalho para entender, que constitui um dos princípios da Prática.

Tal princípio é materializado quando os licenciandos, inseridos no PIBID, na Residência Pedagógica ou estagiando em outros colégios conveniados, desenvolvem atividades pedagógicas com potencial exploratório (APPE), uma noção fundamental na PE (Miller et al., 2008), em que a ideia de planejar para entender se opõe à noção tradicional de planejamento de aula enquanto controle. Nessa direção, privilegia-se a reflexão da própria prática docente, visando ao autoconhecimento e a uma maneira de amenizar as frustrações quando o que é planejado não acontece como esperado. Busca-se, "essencialmente, a qualidade de vida dentro e fora da sala de aula, focalizando a aceitação da diversidade cultural e a riqueza das relações interpessoais" (Barreto; Miller; Góes Monteiro, 2015, p.70).

Sob esse viés, o envolvimento de todos no processo de ensino-aprendizagem, ampliando e estimulando a participação de todos os aprendizes, é um ponto que experienciamos em nossas vivências em sala de aula e acreditamos ser fundamental para que os educandos sintam-se parte do ambiente escolar, reconhecendo nele um vínculo de afeto e um local de mútuas trocas. hooks, pensando na construção de uma pedagogia engajada e transformada, alinha-se a essa ideia: "Cuidar para que todos os alunos cumpram sua responsabilidade de contribuir para o aprendizado na sala de aula não é uma abordagem comum no sistema que Freire chamou de “educação bancária"” (hooks, 2017, p.57).

A fim de chamar os alunos para essa participação de maneira democrática e acolhedora, a inclusão da experiência pessoal mostra-se uma maneira de tornar o ambiente escolar, muitas vezes tido como rígido e pouco flexível, mais próximo, fazendo com que os alunos enxerguem 
a educação como uma ferramenta possível de transformação social e não como algo que não servirá em sua vida posteriormente. Trabalhar com as experiências, logo, "permite aos alunos tomar posse de uma base de conhecimento a partir da qual podem fala"” (hooks, 2017, p.198), além de possibilitar que educandos e educadores se conheçam.

Diante desse cenário, cabe refletirmos sobre o papel dos licenciandos em tal contexto. Nutridos das ideias e dos princípios da Prática Exploratória e da educação como prática da liberdade, acreditamos ser fundamental levar, em nossa prática docente, uma postura crítica e investigativa (Barreto; Miller; Góes Monteiro, 2015). Dessa maneira, esperançando, cremos na possibilidade de uma educação capaz de levar à reflexão e ao pensamento crítico, por meio de uma leitura de mundo e de maior autonomia, com uma "participação mais agentiva, colaborativa e transformadora" (Barreto; Miller; Góes Monteiro, 2015, p.79).

\section{Conclusão}

As reflexões acerca de uma prática libertadora, da qual ainda estamos muito distantes enquanto sistema educacional, só reforçam a importância de se utilizar a obra e a vida de autores como Paulo Freire e Dom Paulo Evaristo Arns como inspiração para a construção de uma educação libertadora, que humaniza o mundo e tem o poder de transformação.

Com essa postura de vivência e reflexão ética e crítica expostas na obra e na vivência de Freire e Dom Paulo, temos o que Rubem Alves (2001) chamou de "escolas asas", as quais “existem para dar aos pássaros coragem para voar”, já que acreditam que é assim que eles devam ser, em oposição às "escolas gaiolas”, que "existem para que os pássaros desaprendam a arte do voo". Tais palavras do escritor reforçam o quão importantes são as escolas que estimulam a autonomia, a individualidade e a liberdade do aluno. Esses conceitos vêm sendo bastante discutidos quando se pensa na figura do educando - ou aprendiz (Grupo da Prática Exploratória, 2020) - e no sistema de ensino em que ele está inserido.

Tanto Freire quanto Dom Paulo nos trouxeram formas e experiências de amor, diálogo e esperança, para além dos muros da sala de aula. Entretanto, neste trabalho, também buscamos ressaltar a importância de os licenciandos estarem atentos a tais ideais e encontrarem, no ambiente em que estão inseridos, liberdade para desenvolverem mutuamente com todos os aprendizes uma prática libertadora. 


\section{Referências bibliográficas}

ALVES, Rubem. Gaiolas e Asas. Opinião/Folha de S. Paulo. São Paulo, 5 dez 2001.

ARROJO, Rosemary; RAJAGOPALAN, Kanavillil. O ensino da leitura e a escamoteação da ideologia. In: ARROJO, Rosemary. (Org.). O Signo Desconstruído: implicações para a tradução, a leitura e o ensino. Campinas: Pontes Editores, 2003. p.87-91.

BARRETO, Beatriz de Castro; MILLER, Inés Kayon de; GÓES MONTEIRO, Maria Cristina Guimarães de. Por que trabalhar com a Prática Exploratória na formação inicial de professores? In: REIS, Cláudia Maria Bokel; SANTOS, William Soares dos. (Org.) Formação de professores de línguas em múltiplos contextos: construindo fontes de saberes e agenciamentos. Campinas: Pontes Editores, 2015, p.57-83.

CORTELlA, Mário Sérgio. Paulo Freire: um pensamento clássico e atual. Revista ecurriculum, São Paulo, v.7, n.3, p.1-14, dez. 2011.

FREIRE, Paulo. A importância do ato de ler: em três artigos que se completam. São Paulo: Cortez, 1989.

FREIRE, Paulo. Educação como prática da liberdade. Rio de Janeiro: Paz e Terra, 2015.

FREIRE, Paulo. Pedagogia da esperança: um reencontro com a Pedagogia do Oprimido. Rio de Janeiro: Paz e Terra, 1992.

FREIRE, Paulo. Pedagogia do oprimido. 74.ed. Rio de Janeiro: Paz e Terra, 2020.

GRUPO DA PRÁTICA EXPLORATÓRIA. Por que trabalhar para entender a vida na sala de aula?: histórias do Grupo da Prática Exploratória. Rio de Janeiro, 2020.

hooks, bell. Ensinando a transgredir: a educação como prática da liberdade. 2.ed. São Paulo: WMF Martins Fontes, 2017.

ALTEMEYER JR., Fernando. Dom Paulo Evaristo Arns, Cardeal da Esperança. Ciberteologia - Revista de Teologia \& Cultura, n.55, p.30-9, 2020.

MILLER, Inés Kayon de. et al. Prática Exploratória: questões e desafios. In: GIL, Glória; VIEIRA-ABRAHÃO, Maria Helena. Educação de professores de línguas: os desafios do formador. Campinas: Pontes Editores, 2008. p.145-65.

VIDAL, Diana Gonçalves. 80 anos do Manifesto dos Pioneiros da Educação Nova: questões para debate. Educação e Pesquisa. São Paulo, vol.39, n.3, p.577-88, 2013. 